\title{
A Study on the Public Aesthetic Perception of Silk Fabrics of Garment -Based on Research Data from Hangzhou, China
}

\author{
Aijuan Cao ${ }^{1,2}$, Lanlan Yan $^{3}$ \& Yiling Zhang ${ }^{1}$ \\ ${ }^{1}$ Fashion \& Art Design Institute, Donghua University, Shanghai, China \\ ${ }^{2}$ Highfashion Womenwear Institute of Hangzhou Vocational \& Technical College, Hangzhou, China \\ ${ }^{3}$ School of Fashion Engineering, Shanghai University of Engineering Science, Shanghai, China \\ Correspondence: Aijuan Cao. E-mail: caoaijuan2005@163.com
}

Received: November 20, 2017

doi:10.5539/ass.v14n2p69

\author{
Accepted: December 19, 2017 Online Published: January 29, 2018 \\ URL: https://doi.org/10.5539/ass.v14n2p69
}

\begin{abstract}
Silk owns a number of excellent qualities, while the perception status of the public on property regarding to silk fabrics of garment is unclear. In this paper, four indicators based on aesthetics as breakthrough point such as gloss, drapability, wrinkle resistance and pilling resistance, were used to analyze the status of the public aesthetic perception of silk fabrics through questionnaire investigation and statistical analysis based on surveys conducted from the public of Hangzhou, China as core objects. The result shows that the public owns high perception on the gloss and drapability of silk fabrics of garment and factors such as gender, personal preference, purchase and use experience, whether the silk industry practitioners are of a significant impact on perception. The higher the monthly income or education level, the higher the perception. Age and life span in Hangzhou are of no significant impact.
\end{abstract}

Keywords: Silk Fabrics, Perception, Aesthetics, Questionnaire Investigation

With the improvement of people's living and aesthetic standards, people's demands for garment appearance are getting higher and higher. Silk fabrics have become the first choice of high-grade garments due to its noble, elegant, soft and flowing property. As one of the three elements of fashion design, appearance and texture, physical properties and plasticity affect the garment appearance directly. The paper will study the aesthetic perception status of silk fabrics of garments as breakthrough point in means of questionnaire investigations and field interviews, aiming to provide some reference data for the development and marketing of silk garment products.

\section{Research Conception and Method}

The garment aesthetics, i.e. the clothing appearance, is to have a good visual and tactile characteristics from the angle of clothing psychology and refined appearance and mechanical appearance in response to fabrics. Most of aesthetic evaluations are based on subjective judgments, but the evaluation method is still a weak spot of garment research till now due to different individual evaluation criteria and clothing preferences (Luo, 2014, p. 46).

Based on consumer interviews and predecessors' research, the author extracted related quantization indicators to develop quantization table for aesthetics perception of silk fabrics of garment and then collected standard quantitative data through questionnaire survey by means of subjective evaluation method based on individual perception. At last, possible statistical law and phenomenon worthy of attention or to further to be explored from the data through the analysis of survey results by means of SPSS statistical method after collection of questionnaires.

\subsection{The Development of Quantization Table}

As fabric is the basis of clothing modeling, good fabric property helps to create beautiful visual effects. Appraisal indicators generally include drapability, stiffness, crease recovery, pilling, wrinkle resistance and flexibility etc.(Shang, 2004, p.5) in view of the property of garment according to relevant literature, colour fastness, stitching performance and shrinkage etc. in view of garment appearance related to fabric according to relevant technical standards, unique luster, distortion and twist after wash, yellowing due to insolation, splitting seams, less patterns and non-fashion etc. in view of silk fabric according to the consumer interviews. It will not 
be considered in this study that yellowing due to insolation, sewing performance (slippery fiber, splitting seams) and colour fastness, deformation (distortion, shrinkage, dimensional stability) correspond to the fabric light resistance, durability and shape preservation respectively, of which are use property of garment and stiffness and flexibility of which belong to the comfort scope of clothing impact mostly on hands' feel. Therefore, the author extracts four common indicators including gloss, drapability, pilling resistance and wrinkle resistance to develop perception quantization table for aesthetics perception of silk fabrics of garment (shown in Table 1).

Table 1. perception quantization table for aesthetics perception of silk fabrics of garment

\begin{tabular}{ccccccc}
\hline SN & Questions & $\begin{array}{c}\text { No } \\
\text { Understanding }\end{array}$ & $\begin{array}{c}\text { Little } \\
\text { Understanding }\end{array}$ & Uncertain & $\begin{array}{c}\text { Basic } \\
\text { Understanding }\end{array}$ & $\begin{array}{c}\text { Full } \\
\text { Understanding }\end{array}$ \\
\hline 1 & The silk fabric gloss is gentle and & 1 & 2 & 3 & 4 & 5 \\
bright. & Drapability of silk fabric is good. & 1 & 2 & 3 & 4 & 5 \\
2 & Silk fabric is not easy to pilling. & 1 & 2 & 3 & 4 & 5 \\
4 & Silk fabric is easy to wrinkle. & 1 & 2 & 3 & 4 & 5 \\
\hline
\end{tabular}

In this study, Cronbach's internal coherence coefficient ( $\alpha$ coefficient) was used to analyze the reliability of the quantization index. When Cronbach's $\alpha$ was less than 0.7, it belongs to low reliability and should be rejected to use. Reliability analysis results show (Table 2) that the $\alpha$ coefficient is 0.873 of the study data through small sample survey, higher than 0.7 obviously, indicating that the questionnaire as a whole with a high degree of reliability to be used.

Table 2. Scale Reliability Analysis

\begin{tabular}{ccc}
\hline Item & N of Items & Cronbach's Alpha \\
\hline Aesthetic Perception & 5 & 0.873 \\
\hline
\end{tabular}

\subsection{Research Methods and Principles}

The questionnaire consists mainly of two parts. In the first part of which is the demographic characteristics of the respondents, including nine aspects as gender, age, the highest education, income, occupation type, personal preferences, life span in Hangzhou, silk fabric purchase experience, whether silk industry practitioners. In the second part of which is on respondents' aesthetic perception of silk fabrics of garment consists of four structural single selection questions, including the fabric gloss, drapability, pilling resistance, wrinkle resistance respectively.

In order to make a statistical analysis of survey results, scores degreed as 1, 2, 3, 4, 5 to "no understanding", "little understand", "uncertain", "basic understanding", "full understanding" respectively according to perceived degree on each indicator of respondents' aesthetic perception of silk fabrics of garment to obtain the perceptual score $\mathrm{Sij}$ of the respondents $\mathrm{i}$ on the natural attributes $\mathrm{j}$ of the silk fabric and then calculate the individual perceptual degree $\mathrm{Si}$ and the single item average perceptual degree $\mathrm{MS}_{\mathrm{j}}$ and average perceptual degree of all the samples. The formula is as follows:

$$
\begin{aligned}
\mathrm{S}_{\mathrm{i}} & =\sum_{j=1}^{5} \mathrm{Sij} \\
\mathrm{MS}_{\mathrm{j}} & =\frac{1}{n} \sum_{i=1}^{n} S i j \\
\mathrm{MS} & =\frac{1}{n} \sum_{j=1}^{5} \quad \sum_{i=1}^{n} S i j
\end{aligned}
$$

The questionnaire data was recorded and analyzed by statistical software SPSS19.0.

\subsection{Sample Composition}

A total of 400 questionnaires were distributed at shopping malls, colleges and subway stations in Hangzhou, and 333 valid questionnaires were collected, of which the effective recovery rate was $83.25 \%$. Among the 333 valid samples, there were 109 males and 224 females, of whom 70 were aged 25 years old and under, 26 were aged from 26 to 35,36 were 45 to 81,46 were 42 to $55 ; 205$ respondents from enterprises or institutions, 85 freelancers and other, 33 students; 101 respondents with monthly income of 3,500 RMB and below, 89 with monthly income of 3501 RMB to $6,000 \mathrm{RMB}, 85$ with monthly income of 6001 RMB to 10,000 RMB, 58 with monthly income of more than 10,000 RMB; 94 with junior college degree and below, 143 with bachelor degree, 96 with master degree and above; 109 with life span in Hangzhou within 1 year, 118 with life span in Hangzhou 
between 1 to 3 years, 35 with life span in Hangzhou between 4 to 10 years, 71 with life span in Hangzhou more than 10 years; 210 silk lovers, 123 non-silk lovers; 262 with silk garment purchase and use experience, 71 without silk garment purchase and use experience; 94 silk industry practitioners, 239 consumers. Respondents covered by questionnaires distribution can basically represent the state of average public perception.

\section{Survey results and analysis}

\subsection{The state of Average Aesthetics Perception of Silk Fabrics of Garment}

The average score of public aesthetics perception of silk fabrics of garment is 4.20 , ranging from high to low gloss (4.35), drape (4.28), pilling resistance (4.19), and wrinkle resistance (3.98) respectively, shown in Figure 1.

The author analyzed the perception difference on each indicator using the silk industry and non-silk industry practitioners as a contrast. It can be seen from Figure 1 that the average perception score (4.62) of the silk industry practitioners is significantly higher than score (4.03) of the non-silk industry practitioners on aesthetics perception of silk fabrics of garment, and the perception scores of the silk industry practitioners on each quantization indicator is higher than those of the non-silk industry. On the one hand, it shows that the questions of the questionnaire are recognized by the industry practitioners and given a high score; on the other hand, the average score of perception state was pulled the silk industry practitioners, while in fact, the general perception level of consumers is relatively low (4.03).

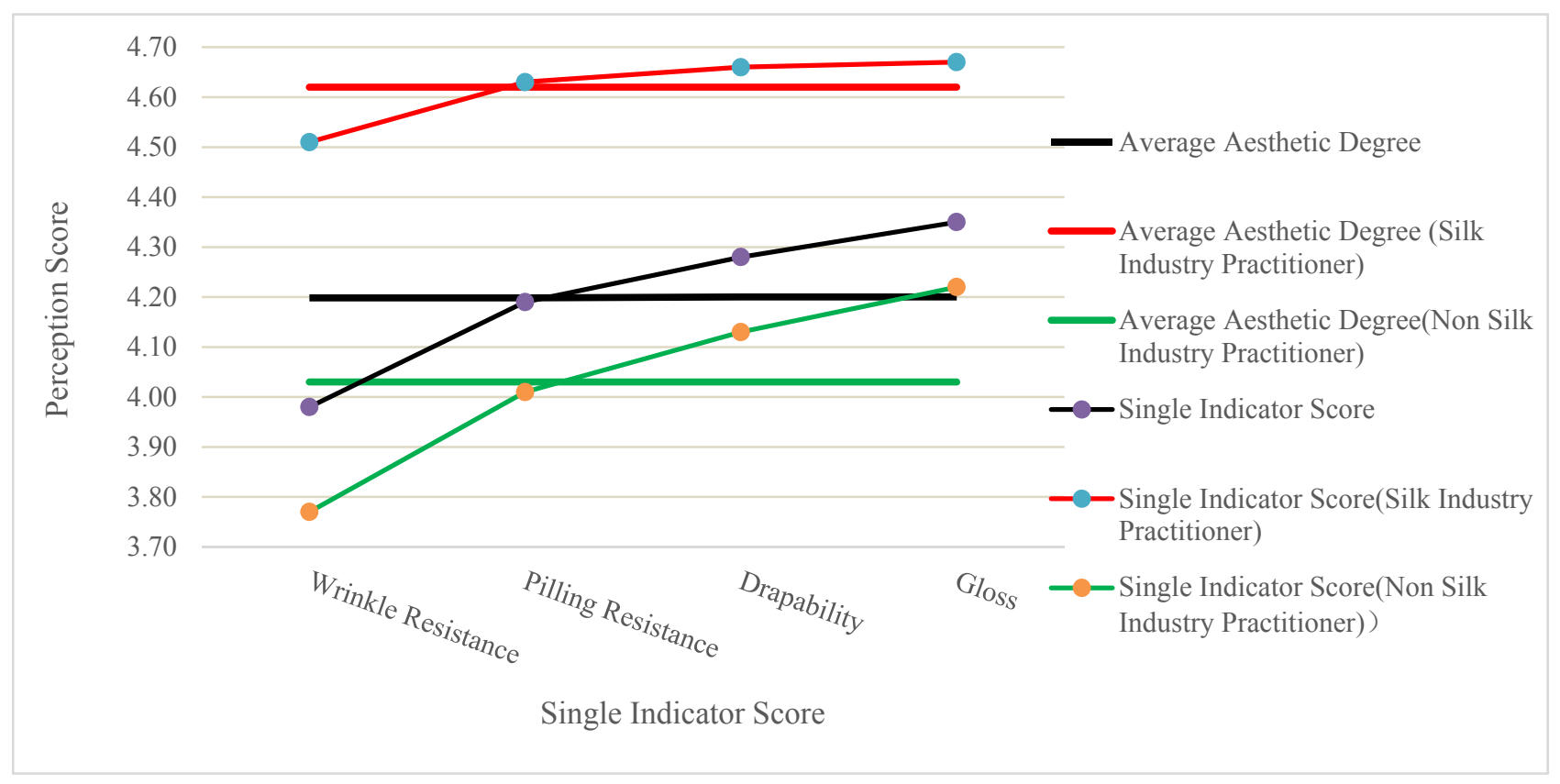

Figure 1. Score on Aesthetics Perception of Silk Fabrics of Garment

\subsubsection{Gloss}

Gloss, referring to the appearance of the fabric color and luster, is impacted by aspects of fiber performance, yarn structure, fabric organization and finishing methods and etc. As the cross-section of silk fiber is triangular or semi-oval, with more reflected light, so the silk fabric color and luster is bright and gentle, elegant and pleasing to the eye, comparable to pearls and ivory, with good visual aesthetics, of which described as "The silk fabric gloss is gentle and bright. " in the questionnaire. On the "gloss" of silk fabrics of garment, the characteristics of respondents with perception score higher than the average 4.35 are: female, aged 45 years and above, working in enterprises or institutions, monthly income of more than 6,000 RMB, postgraduate and above, life span in Hangzhou less than 3 years, silk lovers, with silk garment purchase and use experience and the silk industry practitioners.

\subsubsection{Drapability}

Good drapability is the characteristic that the fabric can form a smooth and curvilinear uniform surface under natural drains (Yao, Zhou \& Huang, 2003, p. 573). The drapability is related to the rigidity of the fabric and is an important factor affecting the appearance of the garment. Silk fabric is with good drapability, wearing fit without shelf feeling, easy to form elegant curved surface modeling on the human body, of which was described as " 
Drapability of silk fabric is good." in the questionnaire. For this feature, the characteristics of respondents with perception score higher than the average 4.28 are: female, aged 25 years and below, working in enterprises or institutions, monthly income of more than 6,000 RMB, undergraduate and above, life span in Hangzhou less than 10 years, silk lovers, with silk garment purchase and use experience and the silk industry practitioners.

\subsubsection{Wrinkle resistance}

Wrinkle resistance refers to the ability of a fabric to resist bending deformation due to rubbing (Yao, Zhou \& Huang, 2003, p. 576). Wrinkle resistance is an important indicator of the appearance of garment evaluation as irregular wrinkles seriously affect the appearance of garment in the process of wearing. The wrinkle resistance of the silk fabric of garment is poor, and wrinkles will appear after a period of wearing, greatly affecting the appearance and quality of the fabric (Xu, 1. \& Zhang, R., 2014, p.27-30), of which was described as "Silk fabric is easy to wrinkle." In the questionnaire. For this feature, the characteristics of respondents with perception score higher than the average 3.98 are: female, aged over 35 years old, working in enterprises or institutions, monthly income of more than 4,500RMB, undergraduate and above, life span in Hangzhou more than 10 years, silk lovers, with silk garment purchase and use experience and the silk industry practitioners.

\subsubsection{Pilling resistance}

Pilling resistance performance is an important indicator of the silk fabric of garment. The fabric fiber of the surface of the garment by the external friction is pulled out to form a ring and pile in the process of wearing and washing, called "fuzzing". If the pile does not fall off in time to reach a certain length entangled with each other, kneaded into a lot of spherical particles, called "pilling". Silk is long fiber, between which the cohesion is relatively strong, and the sericin of the fiber surface has certain viscosity, so the silk fabric is not easy to pilling, of which was described as "Silk fabric is not easy to pilling." in the questionnaire. For this feature, the characteristics of respondents with perception score higher than the average 4.19 are: female, aged 25 years and below, working in the enterprises, monthly income of more than 6,000 RMB, junior college degree and below, life span in Hangzhou less than 10 years, silk lovers, with silk garment purchase and use experience and the silk industry practitioners.

\subsection{Perception Differences in Different Populations}

Regarding to the calculation of public average aesthetic perception MS of silk fabric of the garment by groups, the highest value appeared in population of female, aged over 55, working in enterprises or institutions, monthly income of $6001 \sim 10000$ RMB, postgraduate and above, life span in Hangzhou between 1 to 3 years, silk lovers, with silk garment purchase and use experience and the silk industry practitioners corresponding to gender, age, education, income, occupation, industry, life span in Hangzhou, silk garment purchase and use experience and whether the silk industry practitioners respectively, (see Figure 2).

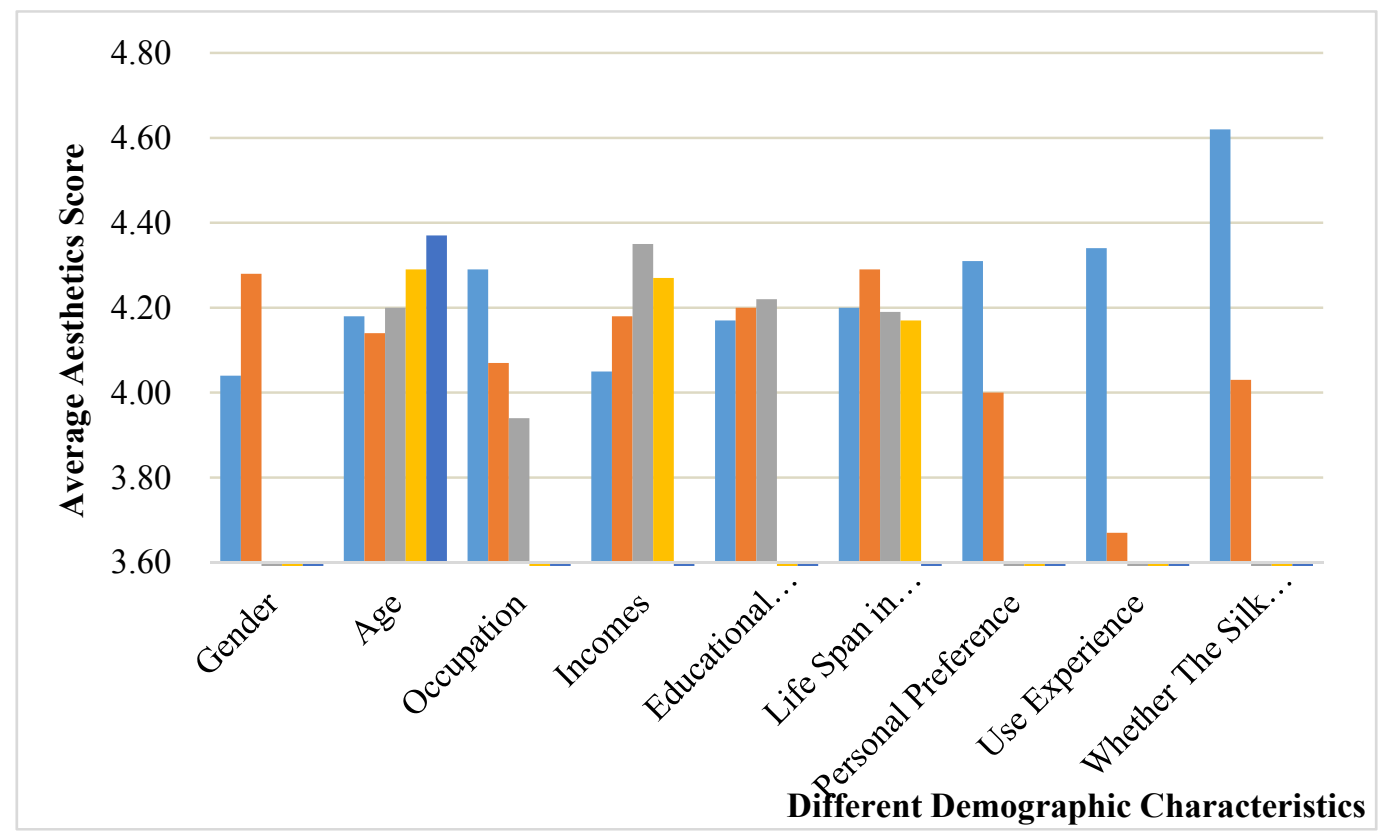

Figure 2. The Average Perception Level of People with Different Demographic Characteristics 
Using individual perception level $\mathrm{Si}$ of different groups as data sample, $\mathrm{T}$ test of independent samples will be taken for those groups with only two comparative data (gender, personal preferences, use experience, whether the silk industry practitioners), and $\mathrm{F}$ test $(\mathrm{P}>0.05$, there is no significant difference) will be taken firstly those groups with three and more comparative data (age, career, income, educational background and life span in Hangzhou) and then further $\mathrm{T}$ test of independent samples on the maximum and minimum population within the group. The results are shown in Table 3.

Table 3. Perception mean difference among populations with different demographic characteristics

\begin{tabular}{|c|c|c|c|c|c|c|c|c|}
\hline \multirow{3}{*}{ Item } & \multicolumn{7}{|c|}{ t-test for Equality of Means } & \multirow{3}{*}{$\begin{array}{c}\text { note } \\
\text { (Comparative } \\
\text { Group) }\end{array}$} \\
\hline & \multirow[t]{2}{*}{$\mathrm{t}$} & \multirow[t]{2}{*}{$\mathrm{df}$} & \multirow[t]{2}{*}{$\begin{array}{c}\text { Sig. } \\
\text { (2-tailed) }\end{array}$} & \multirow[t]{2}{*}{$\begin{array}{c}\text { Mean } \\
\text { Difference }\end{array}$} & \multirow[t]{2}{*}{$\begin{array}{l}\text { Std. Error } \\
\text { Difference }\end{array}$} & \multicolumn{2}{|c|}{$\begin{array}{l}\text { 95\% Confidence } \\
\text { Interval of the } \\
\text { Difference }\end{array}$} & \\
\hline & & & & & & Lower & Upper & \\
\hline Gender & 2.560 & 331 & .011 & .240 & .094 & .056 & .425 & - \\
\hline $\begin{array}{c}\text { Personal } \\
\text { Preferences }\end{array}$ & -3.438 & 331 & .001 & -.311 & .090 & -.489 & .133 & - \\
\hline $\begin{array}{c}\text { Use } \\
\text { Experience }\end{array}$ & -6.643 & 331 & .000 & -.677 & .102 & -.878 & -.477 & \\
\hline $\begin{array}{l}\text { Whether } \\
\text { The Silk } \\
\text { Industry }\end{array}$ & 6.250 & 331 & .000 & -.584 & .0093 & .400 & .767 & - \\
\hline Practitioners & & & & & & & & \\
\hline Age & -1.290 & 138 & .199 & -.235 & .182 & -.596 & .125 & Group 2\& Group 5 \\
\hline Occupation & 2.164 & 298 & .031 & .214 & .099 & .019 & .408 & Group $1 \&$ Group 3 \\
\hline Income & -2.492 & 135 & .014 & -.26294 & .10551 & -.47161 & -.05428 & Group $1 \&$ Group 3 \\
\hline $\begin{array}{l}\text { Educational } \\
\text { Background }\end{array}$ & -.423 & 188 & .673 & -.051 & .121 & -.289 & .187 & Group 1\& Group 3 \\
\hline $\begin{array}{c}\text { Life Span in } \\
\text { Hangzhou }\end{array}$ & .548 & 87 & .585 & .126 & .230 & -.332 & .584 & Group 2\& Group 4 \\
\hline
\end{tabular}

Note. Only the data under the condition of "hypothetical mean difference equals"; sig for the P value.

In the $5 \%$ confidence interval according to the $\mathrm{P}$ value, it was found that there was significant difference ( $\mathrm{P}$ $<0.05$ ) in aesthetic perception among the groups with different gender, personal preferences, use experience and whether the silk industry practitioners. Among which perception level of female (4.28) is significantly higher than that of men (4.04), silk lovers (4.31) is higher than that of non-silk lovers (4.00), people with purchase and use experience (4.62) is significantly higher than that of people without purchase and use experience (4.03) and silk industry practitioners (4.62) are significantly higher than that of non-silk industry practitioners (4.03).There is certain difference within the group of different occupations and income, among which perception level people working in enterprises or institutions (4.29) is significantly higher than that of students (4.94) and the people with income of $6001 \sim 10,000 \mathrm{RMB}(4.35)$ is significantly higher than that of the income of less than 3,500 yuan (4.05). There is no significant difference on aesthetic perception among people of different age, educational background and life span in Hangzhou ( $\mathrm{P}>0.05)$.

\section{Conclusions and Recommendations}

This paper has developed a quantization table of four indicators for aesthetic perception of silk fabric of garment including gloss of appearance, drapability, wrinkle resistance and pilling resistance etc. in means of streamlining garment aesthetic, related literature data and consumer interviews.

The statistical analysis of 333 collected data through the questionnaire survey shows that:

(1) Among the four indicators reflecting aesthetic of silk fabric, the public perception is high in gloss and drapability and low in wrinkle resistance.

(2) Gender, personal preferences, purchase and use experience of garment of silk fabric, whether the silk industry practitioners are of significant factors impact on the aesthetic perception of silk fabric of garment, while age, educational background and life span in Hangzhou are of no significant impact.

(3) Population with low aesthetic perception level (below the average 4.20) on silk fabric of garment appears in: male, age below 35 years, not working in enterprises or institutions, monthly income less than 6,000 RMB, below junior college degree, life span in Hangzhou more than 10 years, individuals do not like silk, without 
purchase and use of experience of silk garment and non-silk industry practitioners.

There are two shortcomings in the study. Firstly, in the consumer interview process, few consumers mentioned that "silk garment in the market looks like designed for middle-aged and elderly people as patterns and styles are a little bit old-fashioned.", "consumer-friendly silk garment either is too fancy or too boring, which is not suitable for young people." and so on. While in the development of small sample survey of "perception quantization table for aesthetics perception of silk fabrics of garment", "silk fabric pattern is less, not fashionable" was removed. Secondly, the study was confined by the quantity of samples and geographical limitations. Hangzhou has always enjoyed the reputation of "The Silk Home, Women's Dress Capital", with a long history of mass production and consumption of silk garment, therefore. Therefore, survey in Hangzhou area is equivalent to give the sample a certain initial knowledge, so that the universality of the survey results remains to be discussed.

\section{Acknowledgments}

The authors would like to thank Donghua University and Hangzhou Vocational \& Technical College. Also, many thanks for the supporting of the project 'Excellent young and middle-age teachers entering enterprise system service of enterprises and academic research joint among universities belonged to Hanzghou'. Meanwhile, thanks for the editor and the readers of Asian Social Science.

\section{References}

Luo, L. (2014). Exploring the Affect of Women's Fit Tailoring on the Design of Contemporary Chinese Women's Beauty. Xi'an: Master's Thesis, Xi'an University of Engineering.

Shang, L. (2004). Study on the Influence of Adhesive Lining And Bonding Process on The Appearance of Clothing. Qingdao: Master's Thesis, Qingdao University. https://doi.org/10.7666/d.y618390

Yao, M., Zhou, J. F., \& Huang, S. Z. (2003). Textile Material. Beijing: China Textile Press.

Xu, L., \& Zhang, R. (2014). Effect of Fixing Agent SE on Wrinkle Resistance of Silk Fabrics. Journal of Silk, 51(4), 27-30. https://doi.org/10.3969/j.issn.1001-7003.2014.04.007

\section{Copyrights}

Copyright for this article is retained by the author(s), with first publication rights granted to the journal.

This is an open-access article distributed under the terms and conditions of the Creative Commons Attribution license (http://creativecommons.org/licenses/by/4.0/). 